\title{
Cross-sectional study of associations between normal body weight with central obesity and hyperuricemia in Japan
}

Takako Shirasawa $^{\text {* }^{*} \text {, Hirotaka Ochiai }}{ }^{1}$, Takahiko Yoshimoto', Satsue Nagahama², Akihiro Watanabe ${ }^{1}$, Reika Yoshida ${ }^{1}$ and Akatsuki Kokaze ${ }^{1}$

\begin{abstract}
Background: Several studies have shown that normal weight with central obesity (NWCO) is associated with cardiovascular disease risk factors such as hypertension, dyslipidemia and diabetes. However, the relationship between NWCO and hyperuricemia has not been studied in detail.
\end{abstract}

Methods: We investigated the association between NWCO and hyperuricemia among Japanese adults aged 40-64 years who had undergone periodic health examinations between April 2013 and March 2014. Obesity was defined as a body mass index (BMI) $\geq 25 \mathrm{~kg} / \mathrm{m}^{2}$ and central obesity was determined as a waist-to-height ratio (WHtR) $\geq 0.5$. We classified the participants into the following groups based according to having obesity and central obesity: normal weight (BMI $18.5-24.9 \mathrm{~kg} / \mathrm{m}^{2}$ ) without (NW; WHtR < 0.5$)$ and with (NWCO) central obesity, and obesity without $(\mathrm{OB})$ and with $(\mathrm{OBCO})$ central obesity. Hyperuricemia was defined as serum uric acid $>7.0$ and $\geq 6.0 \mathrm{mg} / \mathrm{dL}$ in men and women, respectively, or under medical treatment for hyperuricemia. Alcohol intake was classified as yes (daily and occasional consumption) and none (no alcohol consumption). Odds ratios (OR) and 95\% confidence intervals (Cl) for hyperuricemia were calculated using a logistic regression model.

Results: We analyzed data derived from 96,863 participants (69,241 men and 27,622 women). The prevalences of hyperuricemia in men and women were respectively, 21.4 and 11.0\%, and of participants with NWCO respectively 15.6 and $30.0 \%$. The adjusted OR for hyperuricemia was significantly increased in OBCO compared with NW, regardless of sex (men: $\mathrm{OR}, 2.12$; $95 \% \mathrm{Cl} ; 2.03-2.21$; women: $\mathrm{OR}, 3.54 ; 95 \% \mathrm{Cl}, 3.21-3.90$ ) and were statistically significant in NWCO compared with NW (men: OR, 1.44; 95\%Cl, 1.36-1.52; women: OR, 1.41; 95\%Cl, 1.27-1.57). The results were similar regardless of alcohol consumption.

Conclusions: We found that NWCO and OBCO were associated with hyperuricemia in middle-aged Japanese men and women. Middle-aged Japanese adults with normal weight but having central obesity should be screened using a combination of BMI and WHtR and educated about how to prevent hyperuricemia.

Keywords: Normal weight central obesity, Body mass index, Waist-to-height ratio, Hyperuricemia

\footnotetext{
* Correspondence: shirasawa@med.showa-u.ac.jp

${ }^{1}$ Department of Hygiene, Public Health and Preventive Medicine, Showa

University School of Medicine, 1-5-8 Hatanodai, Shinagawa-ku, Tokyo

142-8555, Japan

Full list of author information is available at the end of the article
}

(c) The Author(s). 2020 Open Access This article is distributed under the terms of the Creative Commons Attribution 4.0 International License (http://creativecommons.org/licenses/by/4.0/), which permits unrestricted use, distribution, and reproduction in any medium, provided you give appropriate credit to the original author(s) and the source, provide a link to the Creative Commons license, and indicate if changes were made. The Creative Commons Public Domain Dedication waiver (http://creativecommons.org/publicdomain/zero/1.0/) applies to the data made available in this article, unless otherwise stated. 


\section{Background}

Hyperuricemia is associated with increased risk of gout [1], hypertension, chronic kidney diseases, congestive heart failure, metabolic syndrome, type 2 diabetes mellitus and cardiovascular disease (CVD) [2]. Therefore, the prevention of hyperuricemia is an important public health issue.

Several studies have associated normal weight with central obesity (NWCO), defined by body mass index (BMI) and waist-to-height ratio (WHtR), and the CVD risk factors of hypertension, dyslipidemia and diabetes $[3,4]$. In addition, NWCO is associated with a significantly higher risk for metabolic syndrome [5]. Thus, measuring degrees of central fat distribution appear important for the early detection of health risks, even among individuals with normal weight (NW) [6]. However, relationships between NWCO and hyperuricemia remain obscure.

The present study aimed to determine relationships between NWCO and hyperuricemia among Japanese middle-aged adults. We postulated that Japanese men and women are at higher risk for hyperuricemia when they have NWCO, than NW.

\section{Methods}

\section{Participants}

The present study was a cross-sectional study that used the data $(n=310,577)$ from Japanese men and women who had underwent periodic health examinations conducted by the All Japan Labor Welfare Foundation (Tokyo), between April 2013 and March 2014. The inclusion criteria were individuals aged 40-64 years and those who consented to participate in this study. The exclusion criteria were those who had missing data and who were underweight $\left(\mathrm{BMI}<18.5 \mathrm{~kg} / \mathrm{m}^{2}\right)$.

Of 310,577, 310,498 individuals consented to participate in this study, we excluded 205,730 with missing data and 7905 who were underweight. Thus, we analyzed data from 96,863 participants $(69,241$ men and 27,622 women).

Written informed consent was obtained from the included individuals to participate in the study and to publish their innominate data. The Medical Ethics Committee at Showa University School of Medicine (Approval No. 2132) and the Ethics Committee at the All Japan Labor Welfare Foundation (Approval No. 3-10004) approved the study protocol.

\section{Variables and measurements}

We collected the following information from each participant using a self-administered questionnaire recommended by the Japanese Ministry of Health, Labour and Welfare for specific health examinations [7]: age, sex, alcohol consumption (daily, occasionally, none), smoking status (current, previously smoked, never-smoked), and physical activity equivalent to walking at least $60 \mathrm{~min}$ per day (yes/no). Alcohol intake was classified as yes (daily and occasional consumption) and no (no alcohol consumption) [8].

Trained staff measured the height and weight of the participants in increments of $0.1 \mathrm{~cm}$ and $0.1 \mathrm{~kg}$, respectively, and BMI was calculated as body weight $(\mathrm{kg})$ divided by height squared $\left(\mathrm{m}^{2}\right)$. Waist circumference (WC) was measured to the nearest $0.1 \mathrm{~cm}$ at the level of the umbilicus while standing upright [6]. The WHtR was calculated as WC divided by height. Blood pressure while seated was measured using a HEM-907 automated device (Omron Corporation, Kyoto, Japan).

In accordance with a previous study [9], we defined $\mathrm{OB}$ and NW defined as BMI $\geq 25$ and $18.5-24.9 \mathrm{~kg} / \mathrm{m}^{2}$, respectively. In addition, the presence and absence of $\mathrm{CO}$ were determined as $\mathrm{WHtR} \geq 0.5$ and $<0.5$, respectively [10]. Based on $\mathrm{OB}$ and $\mathrm{CO}$ status, participants in this study were classified as being of normal weight with (NWCO) and without (NW) CO, and as being obese with $(\mathrm{OBCO})$ and without (OB) central obesity [11]. Hypertension was defined as systolic blood pressure $\geq$ $140 \mathrm{mmHg}$, diastolic blood pressure $\geq 90 \mathrm{mmHg}$, or under medication for hypertension [12].

Venous blood samples with drawn from participants to determine serum values of uric acid, high-density lipoprotein cholesterol (HDL-C), low-density lipoprotein cholesterol (LDL-C), triglyceride, blood glucose, and hemoglobin A1c (HbA1c) were stored at $4{ }^{\circ} \mathrm{C}$, transported to and analyzed at a clinical testing laboratory (SRL Inc., Tokyo, Japan) within $24 \mathrm{~h}$.

Serum uric acid was measured using an enzymatic method (AU5400; Beckman Coulter, Brea, CA, USA). Although there was a need to define hyperuricemia in relation to increase uric acid level either by overproduction or due to decrease secretion, in the present study, hyperuricemia was defined as serum uric acid $>7.0 \mathrm{mg} /$ $\mathrm{dL}$ in men or $\geq 6.0 \mathrm{mg} / \mathrm{dL}$ in women, or being under medical treatment for hyperuricemia, which was based solely on serum uric acid levels [13-16]. Serum uric acid levels are lower in women than in men because female hormones decrease them $[17,18]$. These cutoff values were selected as they are generally used in clinical laboratories and have been proposed in previous studies in relation to metabolic syndrome and CVD outcomes to define hyperuricemia $[13-16,19]$. Both HDL-C and LDL-C were determined using a direct method and triglycerides were measured using an enzymatic method (AU5400; Beckman Coulter). Dyslipidemia was defined as $\mathrm{LDL}-\mathrm{C} \geq 140 \mathrm{mg} / \mathrm{dL}$, HDL-C $<40 \mathrm{mg} / \mathrm{dL}$, triglyceride $\geq 150 \mathrm{mg} / \mathrm{dL}$, or under medication for dyslipidemia [20]. Blood glucose values were determined using the hexokinase method (AU5400; Beckman Coulter), and HbA1c 
was measured using a latex agglutination method (JCABM9130; JEOL, Tokyo, Japan). Diabetes was defined as fasting plasma glucose ( $\geq 8 \mathrm{~h}$ after the last caloric intake) $\geq 126 \mathrm{mg} / \mathrm{dL}$, random plasma glucose $\geq 200 \mathrm{mg} / \mathrm{dL}$, HbA1c (National Glycohemoglobin Standardization Program) $\geq 6.5 \%$, or under medication for diabetes mellitus [21].

\section{Statistical analysis}

Data for males and females were separately analyzed, because the serum uric acid distribution differed between them. Characteristics were compared between participants with and without hyperuricemia using unpaired $t$ tests or chi-squared tests. Odds ratios (OR) and 95\% confidence intervals $(\mathrm{CI})$ for hyperuricemia were calculated using a logistic regression model that included age, smoking status, physical activity, hypertension, dyslipidemia, and diabetes to control for potential confounding factors $[11,16]$. Values with $P<0.05$ were considered statistically significant. All data were analyzed using JMP version 13.0 (SAS Institute Japan Co., Ltd., Tokyo, Japan).

\section{Results}

Table 1 shows the characteristics of study participants with mean ages of 50.4 and 50.6 years for men and women, respectively. Means serum uric acid values and the prevalence of hyperuricemia were higher in men than in women (6.1 vs. $4.6 \mathrm{mg} / \mathrm{dL}$ and $21.4 \%$ vs. $11.0 \%$, respectively). The proportions of NWCO among men and women were 15.6 and $30.0 \%$, respectively, and those of men and women who consumed alcohol were 73.2 and $46.3 \%$, respectively.

Tables 2 and 3 respectively show the characteristics of men and women with hyperuricemia and normouricemia. Differences were statistically significant between the nature of the obesity and hyperuricemia in men and women. The prevalences of OBCO in hyperuricemia and normouricemia were 43.3 and $26.7 \%$ among men, and 44.8 and $19.1 \%$ among women. The prevalences of hypertension were 45.2 and $35.3 \%$ in men with hyperuricemia and normouricemia, respectively, and 43.8 and $28.4 \%$ in women with hyperuricemia and normouricemia, respectively. Those of dyslipidemia were 66.0 and $51.1 \%$ in men with hyperuricemia and normouricemia, and 60.7 and $41.0 \%$ in women with hyperuricemia and normouricemia. The prevalences of diabetes among men with hyperuricemia and normouricemia were 7.2 and $9.5 \%$, while those among women with hyperuricemia and normouricemia were 8.0 and $3.6 \%$. Moreover, the proportions of those who habitually consumed alcohol were higher in both men and women with, than without hyperuricemia.
Table 1 Characteristics of participants

\begin{tabular}{|c|c|c|}
\hline & Men $(\mathrm{N}=69,241)$ & Women $(\mathrm{N}=27,622)$ \\
\hline Age (y) & $50.4(7.1)$ & $50.6(6.9)$ \\
\hline Height (cm) & $169.8(6.3)$ & $157.7(6.3)$ \\
\hline Weight (kg) & $69.3(11.0)$ & $57.1(9.8)$ \\
\hline BMI $\left(\mathrm{kg} / \mathrm{m}^{2}\right)$ & $24.0(3.3)$ & $22.9(3.5)$ \\
\hline WC (cm) & $84.8(9.0)$ & $80.5(9.2)$ \\
\hline WHtR & $0.50(0.05)$ & $0.51(0.06)$ \\
\hline \multicolumn{3}{|l|}{ Obesity types } \\
\hline NW & $36,069(52.1)$ & $13,189(47.7)$ \\
\hline NWCO & 10,794 (15.6) & $8,276(30.0)$ \\
\hline $\mathrm{OB}$ & $1,458(2.1)$ & $107(0.4)$ \\
\hline OBCO & $20,920(30.2)$ & $6,050(21.9)$ \\
\hline Uric acid (mg/dL) & $6.1(1.3)$ & $4.6(1.1)$ \\
\hline Hyperuricemia & $14,823(21.4)$ & $3,033(11.0)$ \\
\hline Hypertension & $25,911(37.4)$ & $8,312(30.1)$ \\
\hline Dyslipidemia & $37,557(54.2)$ & $11,918(43.1)$ \\
\hline Diabetes & $6,226(9.0)$ & $1,123(4.1)$ \\
\hline \multicolumn{3}{|l|}{ Smoking status } \\
\hline Current & $29,867(43.1)$ & $5,032(18.2)$ \\
\hline Quit & $13,868(20.0)$ & $2,043(7.4)$ \\
\hline Never smoked & $25,506(36.8)$ & $20,547(74.4)$ \\
\hline \multicolumn{3}{|l|}{ Physical activity } \\
\hline Yes & $22,973(33.2)$ & $8,207(29.7)$ \\
\hline No & $46,268(66.8)$ & $19,415(70.3)$ \\
\hline \multicolumn{3}{|l|}{ Alcohol intake } \\
\hline Yes & $50,624(73.2)$ & $12,784(46.3)$ \\
\hline No & $18,617(26.9)$ & $14,838(53.7)$ \\
\hline
\end{tabular}

Data are expressed as means (standard deviation) or $\mathrm{n}(\%)$ $B M I$ body mass index, $N W$ normal weight without central obesity, NWCO normal weight with central obesity, $O B$ obesity without central obesity, $O B C O$ obesity with central obesity, WC waist circumference, WHtR waist-to-height ratio

Tables 4 and 5 show the crude and adjusted OR and 95\% CI for hyperuricemia among men and women, respectively. The adjusted OR for hyperuricemia was significantly increased in men and women with $\mathrm{OBCO}$ compared with NW after adjustment for age, lifestyle factors, hypertension, dyslipidemia, and diabetes (OR, 2.12; 95\%CI, 2.03-2.21 and OR, 3.54; 95\%CI, 3.21-3.90, respectively). The OR for hyperuricemia were also significantly increased in men and women with NWCO compared with NW (OR, 1.44; 95\%CI, 1.36-1.52 and OR, 1.41; 95\%CI, 1.27-1.57, respectively). An analysis of subgroups stratified by alcohol intake found that the OR for hyperuricemia was significantly increased among men and women with $\mathrm{OBCO}$ who consumed alcohol (OR, 1.95; 95\%CI, 1.86-2.05 and OR, 2.94; 95\%CI, 2.593.35 , respectively) and among those who did not (OR, 3.27; 95\%CI, 2.97-3.60 and OR, 5.29; 95\%CI, 4.50-6.22, 
Table 2 Characteristics of male participants

\begin{tabular}{|c|c|c|c|}
\hline & Hyperuricemia $(\mathrm{N}=14,823)$ & Normouricemia $(\mathrm{N}=54,418)$ & $P^{a}$ \\
\hline Age (y) & $50.0(6.9)$ & $50.6(7.1)$ & $<0.001$ \\
\hline Height (cm) & $170.3(5.9)$ & $169.6(6.3)$ & $<0.001$ \\
\hline Weight (kg) & $73.0(11.8)$ & $68.3(10.6)$ & $<0.001$ \\
\hline BMI $\left(\mathrm{kg} / \mathrm{m}^{2}\right)$ & $25.1(3.6)$ & $23.7(3.2)$ & $<0.001$ \\
\hline WC (cm) & $87.9(9.2)$ & 83.9 (8.7) & $<0.001$ \\
\hline $\mathrm{WHtR}$ & $0.52(0.05)$ & $0.50(0.05)$ & $<0.001$ \\
\hline \multicolumn{4}{|l|}{ Obesity types } \\
\hline NW & $5,722(38.6)$ & $30,347(55.8)$ & \multirow[t]{4}{*}{$<0.001$} \\
\hline NWCO & $2,366(16.0)$ & $8,428(15.5)$ & \\
\hline $\mathrm{OB}$ & $321(2.2)$ & $1,137(2.1)$ & \\
\hline $\mathrm{OBCO}$ & $6,414(43.3)$ & $14,506(26.7)$ & \\
\hline Uric acid (mg/dL) & $7.8(0.8)$ & $5.6(0.9)$ & $<0.001$ \\
\hline Hypertension & 6,694 (45.2) & $19,217(35.3)$ & $<0.001$ \\
\hline Dyslipidemia & $9,779(66.0)$ & $27,778(51.1)$ & $<0.001$ \\
\hline Diabetes & $1,073(7.2)$ & $5,153(9.5)$ & $<0.001$ \\
\hline \multicolumn{4}{|l|}{ Smoking status } \\
\hline Current & 5,915 (39.9) & 23,952 (44.0) & \multirow[t]{3}{*}{$<0.001$} \\
\hline Quit & $3,508(23.7)$ & $10,360(19.0)$ & \\
\hline Never smoked & $5,400(36.4)$ & $20,106(37.0)$ & \\
\hline \multicolumn{4}{|l|}{ Physical activity } \\
\hline Yes & 4,647 (31.4) & $18,326(33.7)$ & \multirow[t]{2}{*}{$<0.001$} \\
\hline No & $10,176(68.7)$ & $36,092(66.3)$ & \\
\hline \multicolumn{4}{|l|}{ Alcohol intake } \\
\hline Yes & $11,860(80.0)$ & $38,764(71.2)$ & \multirow[t]{2}{*}{$<0.001$} \\
\hline No & $2,963(20.0)$ & $15,654(28.8)$ & \\
\hline
\end{tabular}

Data are expressed as means (standard deviation) or $\mathrm{n}(\%)$

$B M I$ body mass index, NW normal weight without central obesity, NWCO normal weight with central obesity, $O B$ obesity without central obesity, $O B C O$ obesity with central obesity, WC waist circumference, WHtR waist-to-height ratio

anpaired t-test or chi-squared test

respectively) compared with NW. The OR for hyperuricemia were statistically significant among men and women with NWCO who consumed alcohol (OR, 1.42; 95\%CI, $1.34-1.51$ and OR, 1.25; 95\%CI, 1.09-1.42, respectively) compared with those who did not consume alcohol (OR, 1.56: 95\%CI, 1.36-1.78 and OR, 1.85; 95\%CI, 1.55-2.21, respectively). These results persisted even after adjustment for age, lifestyle factors, hypertension, dyslipidemia, diabetes, and the estimated glomerular filtration rate.

\section{Discussion}

The present study investigated the relationships between NWCO and hyperuricemia in middle-aged Japanese adults. We found that hyperuricemia was significantly associated with NWCO and OBCO, compared with men and women of NW. The results were similar regardless of alcohol consumption.
The mean serum uric acid value was higher in men than in women. Several studies have investigated serum uric acid levels in Japanese adults. Reported serum uric acid levels for men and women are respectively, 6.2 and $4.4 \mathrm{mg} / \mathrm{dL}$ [14], 5.9 and $4.2 \mathrm{mg} / \mathrm{dL}$ [15], 6.5 and $4.7 \mathrm{mg} /$ $\mathrm{dL}$ [16], and 6.0 and $4.5 \mathrm{mg} / \mathrm{dL}$ [22]. Therefore, our findings of higher serum acid levels in men were similar to these findings.

Several epidemiological studies reported that hyperuricemia was associated with diseases including diabetes mellitus, dyslipidemia, hypertension, CVD, and metabolic syndrome $[2,8,14,16]$. Similarly, the present study showed that the prevalences of hypertension, dyslipidemia, and diabetes were higher with than without hyperuricemia in both men and women. Moreover, we also found that $\mathrm{OBCO}$ significantly increased the OR for hyperuricemia, compared with NW, regardless of sex. Others have positively associated hyperuricemia with obesity in both men and women [16, 23]. Nagahama 
Table 3 Characteristics of female participants

\begin{tabular}{|c|c|c|c|}
\hline & Hyperuricemia $(\mathrm{N}=3,033)$ & Normouricemia $(\mathrm{N}=24,589)$ & $P^{a}$ \\
\hline Age (y) & $51.9(7.0)$ & $50.4(6.9)$ & $<0.001$ \\
\hline Height (cm) & $160.3(8.4)$ & $157.4(5.9)$ & $<0.001$ \\
\hline Weight (kg) & $65.0(12.7)$ & $56.2(8.9)$ & $<0.001$ \\
\hline BMI $\left(\mathrm{kg} / \mathrm{m}^{2}\right)$ & $25.2(4.3)$ & $22.6(3.3)$ & $<0.001$ \\
\hline WC (cm) & $86.9(10.2)$ & 79.7 (8.7) & $<0.001$ \\
\hline $\mathrm{WHtR}$ & $0.54(0.07)$ & $0.51(0.06)$ & $<0.001$ \\
\hline \multicolumn{4}{|l|}{ Obesity types } \\
\hline NW & $826(27.3)$ & $12,363(50.3)$ & \multirow[t]{4}{*}{$<0.001$} \\
\hline NWCO & $823(27.2)$ & $7,453(30.3)$ & \\
\hline $\mathrm{OB}$ & $24(0.8)$ & $83(0.3)$ & \\
\hline $\mathrm{OBCO}$ & $1,360(44.8)$ & $4,690(19.1)$ & \\
\hline Uric acid (mg/dL) & $6.7(0.7)$ & $4.3(0.8)$ & $<0.001$ \\
\hline Hypertension & $1,327(43.8)$ & $6,985(28.4)$ & $<0.001$ \\
\hline Dyslipidemia & $1,840(60.7)$ & $10,078(41.0)$ & $<0.001$ \\
\hline Diabetes & $241(8.0)$ & 882 (3.6) & $<0.001$ \\
\hline \multicolumn{4}{|l|}{ Smoking status } \\
\hline Current & $799(26.3)$ & 4,233 (17.2) & \multirow[t]{3}{*}{$<0.001$} \\
\hline Quit & $396(13.1)$ & $1,647(6.7)$ & \\
\hline Never smoked & $1,838(60.6)$ & $18,709(76.1)$ & \\
\hline \multicolumn{4}{|l|}{ Physical activity } \\
\hline Yes & 868 (28.6) & 7,339 (29.9) & \multirow[t]{2}{*}{0.163} \\
\hline No & 2,165 (71.4) & $17,250(70.2)$ & \\
\hline \multicolumn{4}{|l|}{ Alcohol intake } \\
\hline Yes & $1,780(58.7)$ & $11,004(44.8)$ & \multirow[t]{2}{*}{$<0.001$} \\
\hline No & $1,253(41.3)$ & 13,585 (55.3) & \\
\hline
\end{tabular}

Data are expressed as means (standard deviation) or $\mathrm{n}(\%)$

$B M I$ body mass index, NW normal weight without central obesity, NWCO normal weight with central obesity, $O B$ obesity without central obesity, $O B C O$ obesity with central obesity, WC waist circumference, WHtR waist-to-height ratio

anpaired t-test or chi-squared test

et al. reported that the adjusted OR $(95 \% \mathrm{CI})$ for hyperuricemia in men and women with $\mathrm{BMI} \geq 25 \mathrm{~kg} / \mathrm{m}^{2}$ were $1.75(1.56-1.97)$ and $2.02(1.62-2.53)$ [16]. Yu et al. reported that hyperuricemia was related to abdominal obesity and general obesity in both sexes [23]. The present results are in line with these findings. Even after adjustment for age, lifestyle factors, hypertension, dyslipidemia, and diabetes, our results showed that OBCO had an independently increased risk of hyperuricemia and this was statistically significant between $\mathrm{OBCO}$ and hyperuricemia. As one of the reasons, obesity may increase hyperuricemia through increased urate production and decreased renal clearance, and that renal excretion of urate was also reduced in the presence of insulin resistance [24]. However, the underlying mechanism by which serum uric acid increased in obese individuals still remains to explore [19]. Thus, more studies need to be conducted in order to elucidate the mechanism of the association between serum uric acid and obesity.
In addition to OBCO, NWCO was also significantly associated with hyperuricemia compared with NW. A previous study in Japan found significantly increased OR (95\%CI) for hyperuricemia in men with NWCO compared with NW, but not among women: 1.43 (1.15-1.76) and $2.20(0.36-33.35)$, respectively [6]. We found that NWCO was associated with hyperuricemia risk compared with NW, regardless of sex. Moreover, WC and uric acid levels demonstrated a positive correlation in NW and NWCO group, regardless of sex (men, $\mathrm{r}=0.19 ; P<0.001$, women, $\mathrm{r}=0.23 ; P<0.001$ ). Higher and lower BMI are associated with an increased and decreased prevalence of hyperuricemia, respectively [8]. Therefore, because individuals with NWCO are considered to be of normal weight, they do not usually receive appropriate health education or prompt intervention to prevent hyperuricemia. Our findings suggest that men and women with NWCO need to be identified in addition to those with OBCO, even if their weight is normal. 
Table 4 Odds ratios and 95\% confidence intervals for hyperuricemia in men

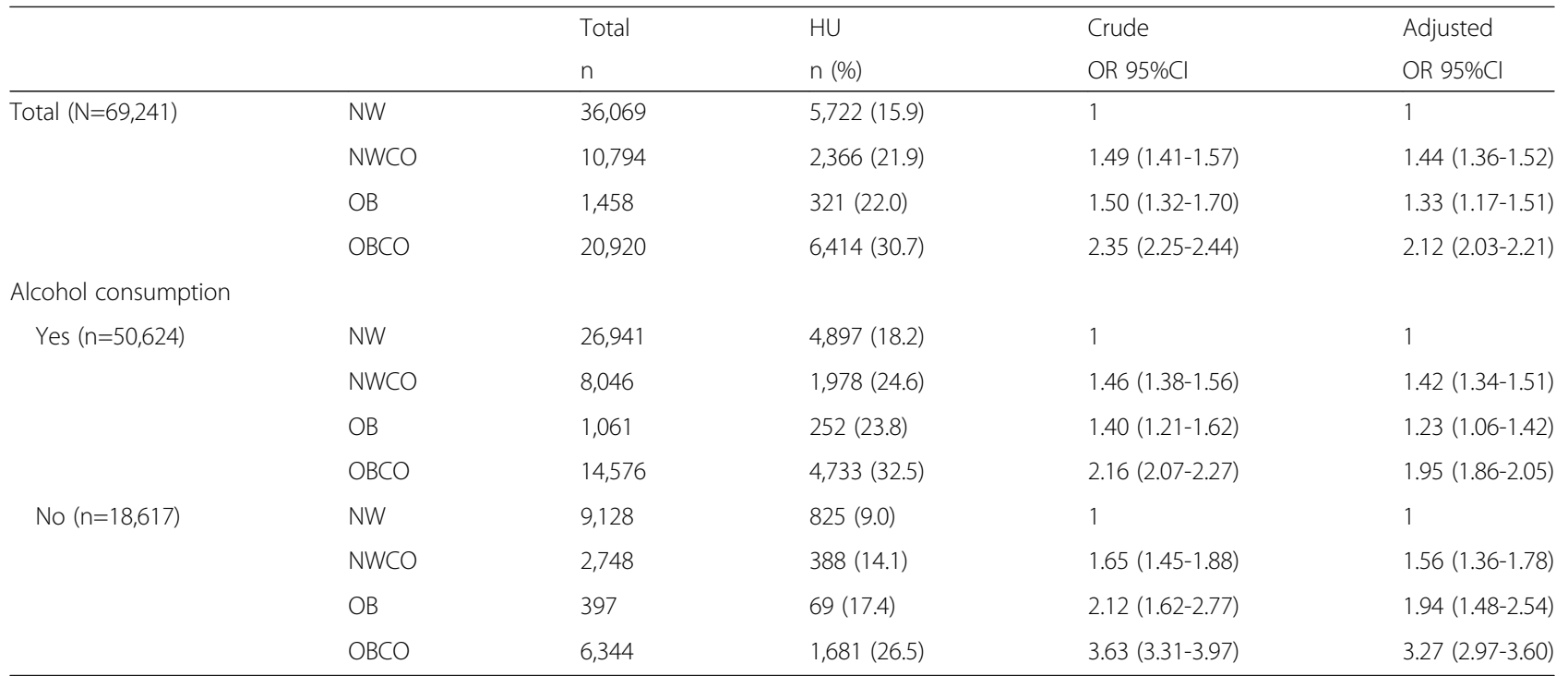

Adjusted for age, smoking status, physical activity, hypertension, dyslipidemia and diabetes

$\mathrm{Cl}$ confidence interval, $H U$ hyperuricemia, NW normal weight without central obesity, NWCO normal weight with central obesity, $O B$ obesity without central obesity, $O B C O$ obesity with central obesity, $O R$ odds ratio

Alcohol consumption is also an important risk factor for hyperuricemia [8, 25-27]. We stratified men and women according to alcohol intake and found that the OR for hyperuricemia were significantly increased in those with OBCO, compared with NW, regardless of alcohol consumption. That is, hyperuricemia was positively associated among men and women with OBCO, regardless of alcohol intake. Moreover, the OR for hyperuricemia were significantly increased in men and women with NWCO, compared with NW, regardless of whether alcohol was consumed. Therefore, screening men and women for NWCO and active intervention to prevent hyperuricemia are important, regardless of alcohol intake.

To the best of our knowledge, this is the first investigation into the relationships between hyperuricemia and NWCO among middle-aged Japanese adults. The strengths of the present study are the large sample size

Table $\mathbf{5}$ Odds ratios and 95\% confidence intervals for hyperuricemia in women

\begin{tabular}{|c|c|c|c|c|c|}
\hline & & Total & $\mathrm{HU}$ & Crude & Adjusted \\
\hline & & $n$ & n (\%) & OR 95\%Cl & OR 95\%Cl \\
\hline \multirow[t]{4}{*}{ Total $(\mathrm{N}=27,622)$} & NW & 13,189 & $826(6.3)$ & 1 & 1 \\
\hline & NWCO & 8,276 & $823(9.9)$ & 1.65 (1.49-1.83) & $1.41(1.27-1.57)$ \\
\hline & $\mathrm{OB}$ & 107 & $24(22.4)$ & $4.33(2.73-6.85)$ & $3.76(2.34-6.02)$ \\
\hline & $\mathrm{OBCO}$ & 6,050 & $1,360(22.5)$ & $4.34(3.96-4.76)$ & $3.54(3.21-3.90)$ \\
\hline \multicolumn{6}{|c|}{ Alcohol consumption } \\
\hline \multirow[t]{4}{*}{ Yes $(n=12,784)$} & NW & 6,467 & $597(9.2)$ & 1 & 1 \\
\hline & NWCO & 3,752 & $491(13.1)$ & $1.48(1.30-1.68)$ & $1.25(1.09-1.42)$ \\
\hline & OB & 60 & $21(35.0)$ & $5.29(3.09-9.06)$ & $4.63(2.66-8.08)$ \\
\hline & $\mathrm{OBCO}$ & 2,505 & $671(26.8)$ & $3.60(3.18-4.06)$ & $2.94(2.59-3.35)$ \\
\hline \multirow[t]{4}{*}{ No $(n=14,838)$} & NW & 6,722 & $229(3.4)$ & 1 & 1 \\
\hline & NWCO & 4,524 & $332(7.3)$ & $2.25(1.89-2.67)$ & $1.85(1.55-2.21)$ \\
\hline & $\mathrm{OB}$ & 47 & $3(6.4)$ & $1.93(0.60-6.27)$ & $1.69(0.51-5.54)$ \\
\hline & $\mathrm{OBCO}$ & 3,545 & $689(19.4)$ & $6.84(5.85-7.99)$ & $5.29(4.50-6.22)$ \\
\hline
\end{tabular}

Adjusted for age, smoking status, physical activity, hypertension, dyslipidemia and diabetes

$\mathrm{Cl}$ confidence interval, $\mathrm{HU}$ hyperuricemia, $N W$ normal weight without central obesity, $N W C O$ normal weight with central obesity, $O B$ obesity without central obesity, $O B C O$ obesity with central obesity, $O R$ odds ratio 
(about 100,000 participants), which helped to decrease random error, and fact that trained technicians measured the anthropometric variables of height, weight and WC of the participants, that were used to define OB and CO. Serum uric acid was measured using a standardized method at a clinical testing laboratory. In contrast, the limitations of the present study include potential confounding factors that were not determined in this study that might have affected our findings. For instance, we did not collect details of dietary intake such as the ingestion of large amounts of purine sources (animal protein and beer) [2]. Another limitation is that the crosssectional study design caused difficulties with assessing causal relationships. For the nature of the study design, we did not observe these weight variations, although weight was very important clinical indicator in order to determine hyperuricemia throughout research in an individual. Thus, further longitudinal studies will be needed to establish causality and to consider weight variation.

\section{Conclusions}

The present study showed that being of NW but having $\mathrm{CO}$, and being obese in general were associated with hyperuricemia among middle-aged Japanese men and women. These findings suggest that middle-aged Japanese men and women with NWCO should be identified using a combination of BMI and WHtR, then educated about the prevention of hyperuricemia.

\section{Abbreviations}

BMI: Body mass index; Cl: Confidence interval; CVD: Cardiovascular disease; HbA1c: Hemoglobin A1c; HDL-C: High-density lipoprotein cholesterol; LDLC: Low-density lipoprotein cholesterol; NW: Normal weight without central obesity; NWCO: Normal weight with central obesity; OB: Obesity without central obesity; OBCO: Obesity with central obesity; OR: Odds ratio; WC: Waist circumference; WHtR: Waist-to-height ratio

\section{Acknowledgements}

The authors thank all the study participants, and Dr. Nobuo Yanagisawa, Dr. Takeshi Kawaguchi, Mr. Takahiro Tamura, and Mr. Yutaka Hoshina at the All Japan Labor Welfare Foundation for supporting this study.

\section{Authors' contributions}

TS, HO, and TY contributed to the study design, interpretation of data and manuscript preparation. TS conducted data analysis and drafted the manuscript. SN contributed to data acquisition. AW and RY contributed to data interpretation. $\mathrm{HO}$ and TY helped to draft the manuscript. AK made substantial contributions to the study concept and project management. All authors have read and approved the final version of the manuscript for publication.

\section{Funding}

This study was supported by a grant from the Ministry of Education, Culture, Sports, Science and Technology of Japan [JSPS KAKENHI Grant Number JP17K09130]. The funder had no role on the design of study and collection, analysis, and interpretation of data and in writing the manuscript in this study.

\section{Availability of data and materials}

The data in this study are available only upon reasonable request and approval by the Ethics Committee of the All Japan Labor Welfare Foundation.

\section{Ethics approval and consent to participate}

The Medical Ethics Committee at Showa University School of Medicine (Approval No. 2132) and the Ethics Committee of the All Japan Labor Welfare Foundation (Approval No. 3-1-0004) approved the study protocol. Written informed consent for the publication of personal information was obtained from all participants.

\section{Consent for publication}

Not applicable.

\section{Competing interests}

The authors declare that they have no competing interests.

\section{Author details}

${ }^{1}$ Department of Hygiene, Public Health and Preventive Medicine, Showa University School of Medicine, 1-5-8 Hatanodai, Shinagawa-ku, Tokyo 142-8555, Japan. ${ }^{2}$ All Japan Labor Welfare Foundation, 6-16-11 Hatanodai, Shinagawa-ku, Tokyo 142-0064, Japan.

Received: 5 September 2019 Accepted: 20 December 2019

Published online: 06 January 2020

\section{References}

1. Shiozawa A, Szabo SM, Bolzani A, Cheung A, Choi HK. Serum uric acid and the risk of incident and recurrent gout: a systematic review. J Rheumatol. 2017:44(3):388-96.

2. Gustafsson D, Unwin R. The pathophysiology of hyperuricaemia and its possible relationship to cardiovascular disease, morbidity and mortality. BMC Nephrol. 2013;14:164.

3. Thaikruea $L$, Thammasarot J. Prevalence of normal weight central obesity among Thai healthcare providers and their association with CVD risk: a cross-sectional study. Sci Rep. 2016;6:37100.

4. Mitsuhashi K, Hashimoto Y, Tanaka M, Toda H, Matsumoto S, Ushigome E, Asano M, Yamazaki M, Oda Y, Fukui M. Combined effect of body mass index and waist-height ratio on incident diabetes; a population based cohort study. J Clin Biochem Nutr. 2017;61(2):118-22.

5. Oliveros E, Somers VK, Sochor O, Goel K, Lopez-Jimenez F. The concept of normal weight obesity. Prog Cardiovasc Dis. 2014;56(4):426-33.

6. Hsieh SD, Yoshinaga H, Muto T. Waist-to-height ratio, a simple and practical index for assessing central fat distribution and metabolic risk in Japanese men and women. Int J Obes Relat Metab Disord. 2003:27(5):610-6.

7. Nagahama S, Kurotani K, Pham NM, Nanri A, Kuwahara K, Dan M, Nishiwaki Y, Mizoue T. Self-reported eating rate and metabolic syndrome in Japanese people: cross-sectional study. BMJ Open. 2014;4(9):e005241.

8. Kuwabara M, Kuwabara R, Niwa K, Hisatome I, Smits G, Roncal-Jimenez CA MacLean PS, Yracheta JM, Ohno M, Lanaspa MA, et al. Different Risk for Hypertension, Diabetes, Dyslipidemia, and Hyperuricemia According to Level of Body Mass Index in Japanese and American Subjects. Nutrients. 2018;10(8).

9. World Health Organization. Body mass index - BMI [http://www.euro.who. int/en/health-topics/disease-prevention/nutrition/a-healthy-lifestyle/bodymass-index-bmi].

10. Browning LM, Hsieh SD, Ashwell M. A systematic review of waist-to-height ratio as a screening tool for the prediction of cardiovascular disease and diabetes: 0.5 could be a suitable global boundary value. Nutr Res Rev. 2010; 23(2):247-69.

11. Owolabi EO, Ter Goon D, Adeniyi OV. Central obesity and normal-weight central obesity among adults attending healthcare facilities in Buffalo City Metropolitan Municipality, South Africa: a cross-sectional study. J Health Popul Nutr. 2017;36(1):54.

12. Shimamoto $K$, Ando K, Fujita T, Hasebe N, Higaki J, Horiuchi M, Imai Y, Imaizumi $T$, Ishimitsu $T$, Ito $M$, et al. The Japanese Society of Hypertension Guidelines for the Management of Hypertension (JSH 2014). Hypertens Res. 2014;37(4):253-390. 
13. Yamanaka $\mathrm{H}$. Japanese guideline for the management of hyperuricemia and gout: second edition. Nucleosides Nucleotides Nucleic Acids. 2011;30(12): 1018-29.

14. Kuwabara M, Kuwabara R, Hisatome I, Niwa K, Roncal-Jimenez CA, Bjornstad P, Andres-Hernando A, Sato Y, Jensen T, Garcia G, et al. "Metabolically Healthy" Obesity and Hyperuricemia Increase Risk for Hypertension and Diabetes: 5-year Japanese Cohort Study. Obesity (Silver Spring, Md). 2017; 25(11):1997-2008.

15. Sonoda H, Takase H, Dohi Y, Kimura G. Uric acid levels predict future development of chronic kidney disease. Am J Nephrol. 2011;33(4):352-7.

16. Nagahama K, Iseki K, Inoue T, Touma T, Ikemiya Y, Takishita S. Hyperuricemia and cardiovascular risk factor clustering in a screened cohort in Okinawa, Japan. Hypertens Res. 2004;27(4):227-33.

17. Adamopoulos D, Vlassopoulos C, Seitanides B, Contoyiannis P, Vassilopoulos $P$. The relationship of sex steroids to uric acid levels in plasma and urine. Acta Endocrinol. 1977;85(1):198-208.

18. Yahyaoui R, Esteva I, Haro-Mora JJ, Almaraz MC, Morcillo S, Rojo-Martinez G, Martinez J, Gomez-Zumaquero JM, Gonzalez I, Hernando V, et al. Effect of long-term administration of cross-sex hormone therapy on serum and urinary uric acid in transsexual persons. J Clin Endocrinol Metab. 2008;93(6): 2230-3.

19. Ali N, Perveen R, Rahman S, Mahmood S, Rahman S, Islam S, Haque T, Sumon AH, Kathak RR, Molla NH, et al. Prevalence of hyperuricemia and the relationship between serum uric acid and obesity: a study on Bangladeshi adults. PLoS One. 2018;13(11):e0206850.

20. Teramoto T, Sasaki J, Ishibashi S, Birou S, Daida H, Dohi S, Equsa G, Hiro T, Hirobe $\mathrm{K}$, lida $\mathrm{M}$, et al. Executive summary of the Japan atherosclerosis society (JAS) guidelines for the diagnosis and prevention of atherosclerotic cardiovascular diseases in Japan -2012 version. J Atheroscler Thromb. 2013; 20(6):517-23.

21. Nanri A, Nakagawa T, Kuwahara K, Yamamoto S, Honda T, Okazaki H, Uehara A, Yamamoto M, Miyamoto T, Kochi T, et al. Development of risk score for predicting 3-year incidence of type 2 diabetes: Japan epidemiology collaboration on occupational health study. PLoS One. 2015;10(11): e0142779.

22. Kawasoe S, Kubozono T, Yoshifuku S, Ojima S, Oketani N, Miyata M, Miyahara H, Maenohara S, Ohishi M. Uric acid level and prevalence of atria fibrillation in a Japanese general population of 285,882. Circ J. 2016;80(12): 2453-9.

23. Yu S, Yang H, Guo X, Zhang X, Zhou Y, Ou Q, Zheng L, Sun Y. Prevalence of hyperuricemia and its correlates in rural northeast Chinese population: from lifestyle risk factors to metabolic comorbidities. Clin Rheumatol. 2016;35(5): 1207-15.

24. Lee J, Sparrow D, Vokonas PS, Landsberg L, Weiss ST. Uric acid and coronary heart disease risk: evidence for a role of uric acid in the obesity-insulin resistance syndrome. The normative aging study. Am J Epidemiol. 1995; 142(3):288-94.

25. Villegas R, Xiang YB, Cai Q, Fazio S, Linton M, Li H, Elasy T, Zheng W, Shu $\mathrm{XO}$. Prevalence and determinants of hyperuricemia in middle-aged, urban Chinese men. Metab Syndr Relat Disord. 2010;8(3):263-70.

26. Nakamura K, Sakurai M, Miura K, Morikawa Y, Yoshita K, Ishizaki M, Kido T, Naruse $\mathrm{Y}$, Suwazono $\mathrm{Y}$, Nakagawa $\mathrm{H}$. Alcohol intake and the risk of hyperuricaemia: a 6-year prospective study in Japanese men. Nutr Metab Cardiovasc Dis. 2012;22(11):989-96.

27. Shiraishi $\mathrm{H}, \mathrm{Une} \mathrm{H}$. The effect of the interaction between obesity and drinking on hyperuricemia in Japanese male office workers. J Epidemiol. 2009;19(1):12-6.

\section{Publisher's Note}

Springer Nature remains neutral with regard to jurisdictional claims in published maps and institutional affiliations.

Ready to submit your research? Choose BMC and benefit from:

- fast, convenient online submission

- thorough peer review by experienced researchers in your field

- rapid publication on acceptance

- support for research data, including large and complex data types

- gold Open Access which fosters wider collaboration and increased citations

- maximum visibility for your research: over $100 \mathrm{M}$ website views per year

At $\mathrm{BMC}$, research is always in progress.

Learn more biomedcentral.com/submissions 